NASA Technical Memorandum 106463

AIAA-94-0852

\title{
Roles, Uses, and Benefits of General Aviation Aircraft in Aerospace Engineering Education
}

Dennis P. O'Donoghue

Sverdrup Technology, Inc.

Lewis Research Center Group

Brook Park, Ohio

and

Robert C. McKnight

National Aeronautics and Space Administration

Lewis Research Center

Cleveland, Ohio

Prepared for the

32nd Aerospace Sciences Meeting and Exhibit

sponsored by the American Institute of Aeronautics and Astronautics

Reno, Nevada, January 10-13, 1994 


\title{
ROLES, USES, AND BENEFITS OF GENERAL AVIATION AIRCRAFT IN AEROSPACE ENGINEERING EDUCATION
}

\author{
Dennis P. O'Donoghue \\ Sverdrup Technology, Inc. \\ Lewis Research Center Group \\ Brook Park, Ohio 44142 \\ and \\ Robert C. McKnight \\ National Aeronautics and Space Administration \\ Lewis Research Center \\ Cleveland, Ohio 44135
}

\begin{abstract}
Many colleges and universities throughout the United States offer outstanding programs in aerospace engineering. In addition to the fundamentals of aerodynamics, propulsion, flight dynamics, and air vehicle design, many of the best programs have in the past provided students the opportunity to design and fly airborne experiments on board various types of aircraft. Sadly, however, the number of institutions offering such "airborne laboratories" has dwindled in recent years. As a result, opportunities for students to apply their classroom knowledge, analytical skills, and engineering judgement to the development and management of flight experiments on an actual aircraft are indeed rare.
\end{abstract}

One major reason for the elimination of flight programs by some institutions, particularly the smaller colleges, is the prohibitive cost of operating and maintaining an aircraft as a flying laboratory. The purpose of this paper is to discuss simple, low-cost, relevant flight experiments that can be performed using readily available general aviation aircraft. This paper will examine flight experiments that have been successfully conducted on board the NASA Lewis Research Center's T-34B aircraft, as part of the NASA/AIAA/University Flight Experiment Program for Students (NAUFEPS) and will discuss how similar experiments could be inexpensively performed on other general aviation aircraft.

The T-34B is a single-engine, propeller-driven, light airplane, representative of many general aviation aircraft. Universities participating in the program include Case Western Reserve University, Cleveland State University, and Baldwin-Wallace College. Experiments conducted under the program, to date, have included topics as varied as microgravity research and remote sensing to airplane performance measurement and air vehicle stability and control characteristics tests.

NASA Lewis has been conducting a joint undergraduate aeronautical engineering education program with Case Western Reserve University since 1992. In this program, undergraduate students in the mechanical/ aerospace engineering curriculum plan flight experiments to measure the performance and stability and control characteristics of the T-34B airplane. As part of the program, the students fly in the rear seat of the aircraft, recording data during the flight. Special instrumentation required to conduct these experiments included a sensitive " $\mathrm{g}$ " meter in the front cockpit to measure vertical accelerations, a stop watch, a portable inclinometer, a tape measure, and data cards to record the data in flight. The response to this program on the part of the students and faculty involved has been overwhelmingly positive. Not only do the students gain an appreciation for the unique environment of flight test, the opportunity to apply their analytical skills and engineering judgement to the analysis of flight test data has proven to be an interesting and rewarding experience. 
NASA Lewis has also been supporting Cleveland State University by providing the T-34B to the mechanical engineering program for microgravity experiments. In this program, the students are tasked with designing the experiment into the aircraft. Again, the students fly in the rear cockpit of the aircraft, monitoring the status of the experiment during microgravity trajectories. Again, the response of the students and faculty to this "hands-on" learning experience has been very positive.

As a final example of the versatility of small aircraft, an aerial remote sensing experiment is discussed. Developed by a senior geology student at Baldwin-Wallace College, this experiment involved using $70 \mathrm{~mm}$ look-down photographic cameras mounted in the underside fuselage of the $\mathrm{T}-34 \mathrm{~B}$, to measure the orientation and speed of currents in a nearby municipal water reservoir, with the goal of identifying mechanisms contributing to poor water quality.

Similar flight programs could be instituted at other universities, either in cooperation with government agencies or through lease or purchase of available general aviation aircraft. Many experiments could be performed with little or no modification to the aircraft, keeping costs to a manageable level. Experience gained from the NASA/AIAA/University Flight experiment Program for Students has demonstrated that limited scope flight experiments have significantly increased the quality and effectiveness of the engineering and science programs of the participating universities.

\section{INTRODUCTION}

Since April of 1992, the NASA Lewis Research Center T-34B (figs. 1 and 2) has been used for two types of university student experiments in the NASA/AIAA/University Flight Experiment Program for Students (NAUFEPS) program and was proposed for use in a third type of experiment. The first type is comprised of determining the aircraft's performance and stability and control parameters while the second type involves flying zero gravity trajectories to study the properties of a liquid in zero and near-zero gravity conditions. The third type that was proposed, approved, and planned, was to perform remote sensing of a water reservoir to measure the current flow in it. However, the experiment was cancelled for reasons unrelated to the NAUFEPS program and is included in this paper as another example flight experiment that would be easily achievable with a general aviation-type aircraft.

An important feature of NAUFEPS has been the opportunities it has created for students to accompany their experiments on the aircraft. By performing their experiments in the dynamic flight environment they have gained practical, hands-on experience they can carry into their professional careers. To make this possible, NASA and the participating universities had to address the legal liability issue as well as the issue of physical fitness for flight. As a result, the students and faculty wishing to fly with their experiments were required to pass a physical exam equivalent to the FAA Class III exam as well as sign a NASA "Release of Claims" form. Some of the students and faculty were also required to sign similar releases from their university. To date, all students and faculty accompanying their experiments have flown enthusiastically and without incident, except for a few mild cases of air sickness.

To initiate their experiments, the students and faculty advisors submitted proposals to Lewis' Office of Educational Services. The proposals, usually structured per the requirements in the NAUFEPS Announcement of Opportunity, addressed the following factors:

1. Objective - Phenomena that would be studied and why the experiment would be important from an undergraduate science education standpoint. 
2. Experiment Description - General method of experiment preparation, data acquisition, data reduction, and reporting of the results.

3. Flight Requirements - General flight profile requirements such as speeds, altitudes, and the like, along with weather requirements, flight location needed (if outside of local Cleveland area), any special ground support requirements, and the approximate number of flights required.

4. Instrumentation and Equipment Required - Additional equipment and/or instrumentation that would be needed along with the source of each; such as NASA, the university, or some other organization.

5. Course of Study - Aerospace science-related course the experiment will support. Proportion of course grade the experiment will be credited towards.

Once the Office of Educational Services approved the experiment for funding, the students and faculty worked with the authors to plan the experiment in detail so that it was achievable within the constraints of the aircraft, the university, and NASA.

\section{CASE WESTERN RESERVE UNIVERSITY PERFORMANCE AND STABILITY AND CONTROL EXPERIMENTS}

For the past two years, Case Western Reserve University's Department of Mechanical and Aerospace Engineering has participated in NAUFEPS. For course credit in the Flight Dynamics and Flight Mechanics and Propulsion courses, engineering juniors and seniors, with the guidance of their course instructors accomplished performance or stability and control experiments with the T-34B.

Although the aircraft was not specially instrumented for these type experiments, they were designed so that little else was needed beyond what would be found on a typical general aviation aircraft. The only instrumentation added was a sensitive inclinometer and sensitive $G$ meter, both mounted in the front cockpit. The inclinometer was used to measure longitudinal pitch angle of the aircraft at wings level steady state points. As a low cost substitute for angle of attack, the pitch angle information was deemed accurate enough for the student experiment. The calibrated sensitive $\mathrm{G}$ meter, graduated in $0.2 \mathrm{G}$ increments, was required because of its higher resolution over the aircraft's standard $\mathrm{G}$ meter. The inclinometer was readily available from NASA Lewis Research Center's Aircraft Maintenance Branch, where it is routinely used for checking the alignment of aircraft structures. The sensitive $G$ meter was readily available, as well, since it is a simple mechanical device.

For these experiments, the Aircraft Operations Branch also provided to CWRU the aircraft engine power charts and calibration tables for the aircraft's altimeters and airspeed indicators. Engine power charts, which give the brake horsepower the engine will develop at various combinations of engine settings and atmospheric conditions, are normally available in most general aviation aircraft flight manuals. The altimeter and airspeed indicator calibrations were generated by testing the instruments with a pitot/static test set, a common piece of aircraft maintenance equipment.

With assistance from this paper's authors, research pilots familiar with the T-34B, the students and course instructors designed the test points and data reduction processes so as to calculate a number of the aircraft's characteristics. These are the T-34B's drag polar, lift curve, span efficiency, propeller efficiency, longitudinal coefficients of damping, lateral-directional coefficients of damping, sustained turn performance, and so forth. 


\section{Test Flight Procedures}

Prior to flight, each student determined his weight and the pilot's weight for later calculation of the aircraft's weight and center of gravity.

In general, the pilot read the test instruments and verbally relayed the numbers to the student engineer via the aircraft's intercom. The student was responsible for writing down the information on the test cards and monitoring the progress of the test points.

Fuel quantity readings were done with the aircraft in level flight at a speed of about $120 \mathrm{kn}$. Since the fuel quantity gauges operate from floats in the tanks, readings at high and low pitch angles were inaccurate. As a back-up, the students recorded the clock time when each test maneuver was performed and assumed a fuel burnoff rate of 11 gallons per hour since the last fuel reading.

Climb.-The pilot would initiate a full power climb at $1500 \mathrm{ft}$ and stabilize on a selected speed of 70,80 , $90,100,110$, or $120 \mathrm{kn}$. The pilot would maintain the selected speed throughout the climb to $6000 \mathrm{ft}$. Passing $2000 \mathrm{ft}$, the pilot would start the stopwatch and read engine manifold pressure and rpm along with outside air temperature. At $60 \mathrm{sec}$ intervals thereafter, the pilot would read altitude, engine manifold pressure and rpm, and outside air temperature. The pilot would also read the fuel quantity immediately before and after the climb.

Level Flight.-The pilot would maintain an altitude of 3000,6000 , or $8000 \mathrm{ft}$ and would adjust engine power to maintain a speed of $60,65,70,80,90,100,110$, or $120 \mathrm{kn}$ with flaps up and speeds of $50,55,60,65$, 70,80 , or $90 \mathrm{kn}$ with flaps down 50 percent. Once stabilized, he would read speed, altitude, inclinometer angle, altitude, outside air temperature, and engine manifold pressure and rpm. He would also read the fuel quantity immediately before or after the point.

Level Acceleration.-While maintaining level flight at 2000,3000,6000, or $8000 \mathrm{ft}$, the pilot would slow the aircraft to $70 \mathrm{kn}$ and initiate a full power level acceleration. He would first read altitude and outside air temperature and then engine manifold pressure and rpm. At $80 \mathrm{kn}$, he would start his stopwatch and read altitude deviations from initial altitude, then at $10 \mathrm{kn}$ increments, read the elapsed time and altitude deviation. At the last point, he would also read the engine manifold pressure and rpm. Immediately before or after the acceleration, the pilot would get a fuel reading.

Sustained Turn Performance.-In level flight at 6000 or $2000 \mathrm{ft}$, the pilot would establish the aircraft in a full power turn at a speed of $80,90,100,110,120$, or $130 \mathrm{kn}$. (These speeds approximate minimum level flight speed plus 10,20 and $30 \mathrm{kn}$, and max level flight speed minus 10,20 , and $30 \mathrm{kn}$.) Once stabilized, the pilot would read the $G$ level that must be sustained to maintain the aircraft in a level sustained performance turn. The pilot would also read the fuel quantity immediately before or after the point.

Phugoid Oscillation Characteristics.-At $6000 \mathrm{ft}$, the pilot would induce a phugoid oscillation at an entry speed of 80 or $130 \mathrm{kn}$. To initiate the phugoid, the pilot would establish steady level trimmed flight at the entry speed, then pitch up to decrease speed by $20 \mathrm{kn}$ and release the controls. After the aircraft descended to the lower apex of the oscillation, the pilot would start the stopwatch and read the altitude and speed. At each of the apex's, the pilot would read elapsed time, altitude, and speed until the oscillation dampened out. The pilot would also take a fuel quantity reading either before or after the maneuver.

Lateral Directional Dutch Roll Characteristics:-At an altitude of $6000 \mathrm{ft}$, the pilot would stabilize the aircraft in level flight at 80 or $130 \mathrm{kn}$. He would then apply a rudder pedal doublet input to excite the dutch roll oscillation, measure the period of the oscillation then count the number of cycles (overshoots) the aircraft would 
make before dampening out. Next, he would excite the dutch roll mode with a rudder doublet and, the student engineer judged the $\phi / \beta$ ratio of the aircraft by observing the pattem that the wing tip scribes on the horizon.

\section{Date Reduction}

In reducing the flight test data, the students had the opportunity to deal with a number of practical flight test problems not commonly addressed in classroom aerodynamic theory. For instance, as a series of test points were being flown, the aircraft's weight was continuously decreasing as fuel was being consumed. In addition, the points were flown at a wide variety of altitudes, mostly dictated by the need to be in smooth air and to stay clear of other air traffic. Further, data accuracy was affected by the inevitable ripples of air turbulence encountered even during smooth air flight test conditions and by human-induced variations in flying and recording each test point.

For example, to establish a usable curve of engine brake horsepower required verses steady level airspeed, the students had to convert their data from a variety of test point altitudes and aircraft weights to a common standard. Once converted and plotted, they had to deal with the data scatter to generate a representative curve, commonly known as the PIW $\times$ VIW curve.

They used the following relation to make the conversion to a common standard:

$$
\begin{aligned}
& \mathrm{PIW}=\frac{\mathrm{BHP}_{\mathrm{R}} \sqrt{\sigma}}{\left(\mathrm{W}_{\mathrm{T}} / \mathrm{W}_{\mathrm{S}}\right)^{3 / 2}} \\
& \mathrm{VIW}=\frac{\mathrm{V}_{\mathrm{c}}}{\left|\mathrm{W}_{\mathrm{T}} / \mathrm{W}_{\mathrm{S}}\right|^{1 / 2}}
\end{aligned}
$$

where

PIW Brake horsepower required at sea level standard day conditions at aircraft's maximum gross weight to maintain steady level flight at a speed of VIW.

VTW Calibrated airspeed at sea level standard day conditions at aircraft's maximum gross weight.

$\mathrm{BHP}_{\mathbf{R}} \quad$ Brake horsepower required at test point.

$\mathrm{V}_{\mathrm{C}} \quad$ Calibrated airspeed at test point.

$\sigma \quad$ Atmospheric density ratio test point/sea level.

$\mathrm{W}_{\mathrm{T}} \quad$ Aircraft weight during test point.

$\mathrm{W}_{\mathrm{S}} \quad$ Maximum allowable gross weight of the aircraft. 
The students then geometrically averaged out the data scatter by plotting the points on a graph of the linear relationship; (PIW) (VIW) $\times(\text { VIW })^{4}$; drawing a central line through the data scatter, and then converting the line back to a PIW $\times$ VIW relationship (figs. 3 and 4 ).

\section{CLEVELAND STATE UNIVERSITY MICROGRAVITY EXPERIMENT}

Two senior mechanical engineering students, with the assistance of their faculty advisor and a number of science professionals from NASA Lewis, performed a microgravity fluids student experiment with the T-34B. The experiment's objective was to use capillary rise phenomena to characterize fractional gravity levels experienced in the T-34B while flying microgravity arcs (parabolic trajectories). The experiment method was to measure the capillary action of water in an experiment package aboard the aircraft, then calculate the " $G$ " levels that produced the action.

\section{Experiment Design}

A major portion of the student's effort towards this experiment was their design and development of the capillary tube experiment package and its installation into the aircraft. Besides needing to produce accurate, reliable data, their design had to meet NASA airworthiness requirements and be approved through a NASA Lewis safety review process. In addition, the NASA Lewis Aircraft Operations Branch researched the suitability of the T-34B for performing microgravity arcs and developed flight procedures so as to provide about $10 \mathrm{sec}$ of microgravity conditions during each arc (ref. 3).

The experiment package consisted of an array of capillary tubes and reservoirs mounted in front of a measurement grid. Also, mounted next to the grid was a sensitive spring weight accelerometer which was added to provide an indication of $\mathrm{g}$ level independent of the capillary action. At the other end of the package was a video camera, which recorded the capillary action of water in the tubes and spring-weight accelerometer indications in relation to the measurement grid. The package was mounted to an experiment platform between the T-34B's front and rear cockpits (figs. 5 and 7).

Another piece of equipment necessary for the experiment was designed for the pilot's cockpit. This was a sensitive spring-weight accelerometer similar to the one on the experiment package. By using the sensitive accelerometer as a guidance display for flying the arc, the pilot was able to produce steadier, more accurate microgravity conditions than if a conventional aircraft " $\mathrm{G}$ " meter with a coarse scale were used (fig. 7).

For sizing the capillary tubes, the students used the Bond number relation, where the Bond number is close to 1 during microgravity arcs when the surface tension and gravitational forces are nearly equal.

$B_{O}$ Bond number

$$
\mathrm{B}_{\mathrm{O}}=\frac{\alpha \rho \mathrm{R}^{2}}{\gamma}
$$

$\rho$ Density of liquid $\left(\mathrm{H}_{2} \mathrm{O}\right)$

$\alpha$. Acceleration of gravity

$\mathrm{R}$ Radius of capillary tube

$\gamma \quad$ Surface tension of water

Once the radii of the capillary tubes were established, the students could measure the fractional " $G$ " levels from capillary indications based on the relation:

$$
\gamma_{1}=1 / 2[\mathrm{H}+(\mathrm{R} / 3)] \rho \mathrm{R} \alpha
$$



$\alpha \quad$ Acceleration of gravity
$R$ Radius of capillary tubes
$\gamma_{1}$ Surface tension of water
$\rho$ Density of liquid $\left(\mathrm{H}_{2} \mathrm{O}\right)$
$\mathrm{H}$ Rise height of fluid

\section{Experiment Results}

As a learning experience, the student experiment was highly successful. For example, after studying the video tapes from the first microgravity flight, the students felt that their capillary tube design worked very poorly. They determined that unwanted capillary action in the reservoirs and vent tubes in combination with restrictions to venting were preventing proper capillary action. In addition, they learned that a handbook value of water's surface tension they had used to size the capillary tubes was far from the actual value, determined by test, for the water used in the experiment. The students then redesigned the tube array into an alternate configuration with smaller diameter capillary tubes and an improved vent system (fig. 6). Another microgravity flight was then performed with the alternate configuration. The video tapes from the flight showed significant improvement, although they indicated there may be a few more less significant engineering problems that need to be handled to obtain reliable data.

For instance, the students found that " $G$ " forces acting on the fluid in the aircraft's longitudinal axis during microgravity flight were often large enough to overwhelm the microgravity forces and capillary forces in the vertical axis. The results seem to indicate that an improved pilot guidance display is needed that will give longitudinal axis guidance as well as that for the vertical axis.

By the time they completed their independent studies course involving the experiment, the students and their faculty advisor were quite pleased with the progress they had made on this ambitious project. In the future, Cleveland State hopes to use the experiment package and guidance display for follow-on projects involving student engineer design, development, and experimentation with the T-34B.

Many other general aviation aircraft could be adapted for small, simple, microgravity experiments. Several factors should be considered when selecting an aircraft for this type experiment. First, it is vital to insure that the aircraft's oil and fuel system will operate sufficiently well during sustained microgravity, even if the aircraft has "inverted flight" or "aerobatic" systems. On the other hand, the short period of time over which the microgravity is typically sustained helps make it possible for many engines and propellers to successfully operate during microgravity. For example, the T-34B's engine and propeller are limited to $15 \mathrm{sec}$ of operation at zero g, which has not presented a problem in performing 10-sec arcs. Second, the maximum speed to which the aircraft can be accelerated will, to a great extent, govern the amount of microgravity time that can be provided during each arc. The T-34B, for example, is accelerated to almost $240 \mathrm{kn}$ indicated, then pulled up to $45^{\circ}$ of pitch to start the arc that, once it is stabilized close to zero $\mathrm{g}$, lasts about $10 \mathrm{sec}$. Although many general aviation aircraft have slower limiting speeds, microgravity times on the order of $5 \mathrm{sec}$ would probably be useful for many experiments. Third, the vibration level in the aircraft, especially when powered by a reciprocating engine, should be carefully considered. Vibration forces can become very significant on some types of experiments when gravity forces are near zero, which may make it necessary to add considerable vibration isolation padding when mounting some experiments. 


\section{BALDWIN WALLACE COLLEGE PROPOSED REMOTE SENSING EXPERIMENT}

In early 1993, a student and faculty advisor from the Geology Department proposed a senior research project involving Lewis' T-34B. The proposal was to measure current flow through a municipal water reservoir via photographic remote sensing from the aircraft of dye inserted into the current, then calculate the future channel development expected to occur in the reservoir. (Channel development was believed to be critical to the quality of water that could be supplied from the reservoir in future years.)

Lewis' T-34B is well suited to the remote sensing task because of the photography and navigation system it is equipped with. Other general aviation aircraft could be similarly equipped, as well, at fairly low cost. Two $70 \mathrm{~mm}$ format cameras mounted in the floor of the aircraft's baggage compartment are the main components of the photography system. The cameras, which are remotely triggered from the aircraft's cockpit, look downward through two glass view ports installed in the underside of the aircraft. Although these cameras are mounted internally, many other simple camera installations are available for mounting look-down cameras onto general aviation aircraft struts, passenger doors, and baggage compartment doors.

The aircraft is equipped with a GPS navigation unit designed and priced for the general aviation market. However, it has many features, as do other manufacturer's general aviation units, that are very desirable for remote sensing. First, it can determine aircraft position within $100 \mathrm{~m}$ without a differential input. With differential corrections, it's accuracy increases to within $15 \mathrm{~m}$. Second, the unit can accept and process coordinates in not only the cartesian latitude/longitude format, but in the UTM "grid square" format as well. This allows easier, more accurate generation of flight lines from the U.S. Geological Survey quadrangle charts. Finally, the unit's lateral course deviation guidance display can be set to a very high sensitivity so that photo flight line off course indications corresponding to as little as $15 \mathrm{~m}$ can be presented to the pilot.

For planning the remote sensing flight, the student first determined where along and within the reservoir the dye could be inserted. Next, from a U.S. Geological Survey quadrangle map of the area, the student determined the coordinates of a photo flight line favorably oriented with the dye insertion points (fig. 8). Finally, the student determined how much of the reservoir each photo must encompass and from the geometry of the cameras and lenses calculated the required aircraft altitude for the flight line.

\section{Test Procedure}

The test procedure was for personnel at the reservoir to release the dye, a safe chemical named RhodaminWT, in coordination with the student and pilot orbiting a short distance away. The pilot and student would then fly the aircraft and cameras on the flight line at the specified altitude at five and 15 minutes after dye insertion. Along the flight line, the student would operate the cameras to take photos of the dye trace in black and white (Kodak Aerographic $2424 \mathrm{film}$ ) and infrared (Kodak Aerochrome 2443 film). The photo results were expected to be similar to another dye release experiment done with the T-34B at an Ohio natural resources area (fig. 9).

\section{Data Reduction}

Data reduction would have been to first calculate the geometric scale of the photos, based upon actual aircraft altitude, camera/lens geometry, and size of the photo image. Then the student would have measured the dye trace's dimensions and orientation on the photo images to determine the speeds and directions of the current. 


\section{AIRCRAFT COSTS}

General aviation aircraft, designed for purchase and operation in a competitive marketplace, can be used at relatively low cost for these type experiments. Further, a number of experiments could be accomplished with lower performance, less complex aircraft than the T-34B, which would probably reduce the costs even further.

Typical costs of ownership and operation are reflected in rental rates for these type aircraft. For example, a Beech Bonanza, an aircraft similar to the T-34B in systems complexity and engine size, rents for about $\$ 100.00$ per flight hour, including fuel, in the northeast Ohio area. A Cessna 172, which is equipped with a smaller engine, and simpler propeller and landing gear system, rents for about $\$ 65.00$ per hour; while a basic, twoperson Cessna 150 is about $\$ 50.00$ per hour.

\section{CONCLUSION}

Since initiation of the NAUFEPS program, NASA Lewis and the participating universities have demonstrated that simple, low cost, but relevant flight experiments for students can be successfully performed with a general aviation-type aircraft. Other institutions, as well, could economically provide students meaningful learning experiences through similar use of general aviation aircraft.

\section{REFERENCES}

1. "Announcement of Research Opportunity for Undergraduate Students", R.C. McKnight, NASA Lewis Research Center, C.J. Pestak, AIAA Northern Ohio Section, Cleveland, Ohio, September, 1991.

2. NATOPS Flight Manual, Model T-34B, NAVAIR 01-90 KDB-1, U.S. Navy, March, 1981.

3. "Operations Plan - Performance of Microgravity Arcs with the T-34B Aircraft", R.C. McKnight, NASA Lewis Research Center, Cleveland, Ohio, December 8, 1992.

4. MCE 499 Special Topics "NASA T-34 Microgravity Experiment", D. Lapeus, K. Kriedeman, Cleveland State University, Mechanical Engineering Department, Cleveland, Ohio, March 12, 1993.

5. Memo - "Student Experimenter Eligibility for Flight on Lewis T-34 Aircraft" from NASA Lewis Office of Chief Counsel to Chief, Office of Educational Programs, NASA Lewis Research Center, Cleveland, Ohio, September 22, 1992.

6. "TNL 3000 GPS/LORAN Pilot Guide", TPN 80354-0304, Trimble Navigation, Austin, Texas. 


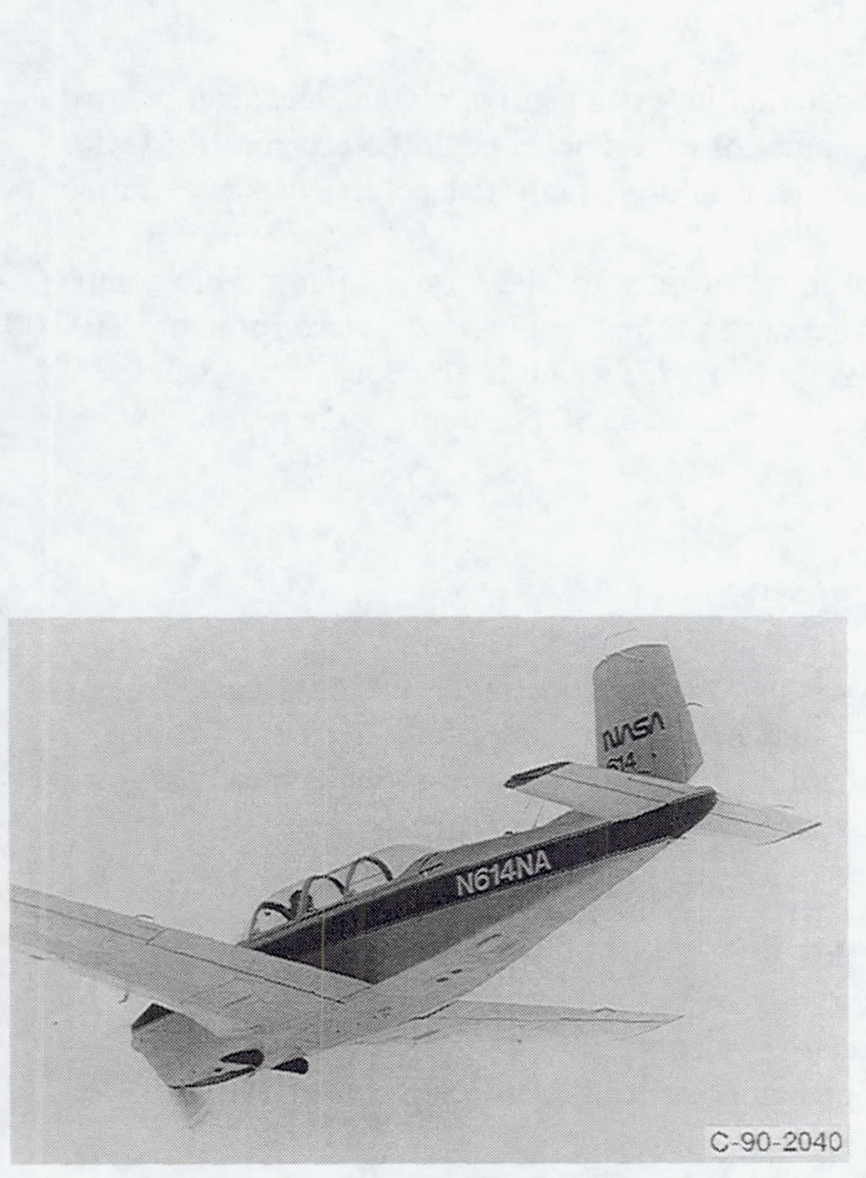

Figure 1.-NASA Lewis T-34B.

\begin{tabular}{|c|c|}
\hline $\begin{array}{l}\text { Experiment weight } \\
\text { capacity }\end{array}$ & $\sim 25 \mathrm{lbs}$ \\
\hline Seating & $\begin{array}{l}\text { Rear cockpit available for } \\
\text { one experimenter }\end{array}$ \\
\hline Speed/altitude & $\begin{array}{l}\text { 120 knots indicated air speed } \\
\text { cruise } \\
50 \text { KIAS stall } \\
240 \text { KIAS max structural speed } \\
\text { limit } \\
12,500 \mathrm{ft} \text { max altitude } \\
\text { (unpressurized) }\end{array}$ \\
\hline Endurance & $\sim 120$ minutes \\
\hline $\begin{array}{l}\text { Electrical system } \\
\text { capability for } \\
\text { experiments }\end{array}$ & $\begin{array}{l}28 V D C-20 A \\
12 V D C-6 A\end{array}$ \\
\hline Flight controls & Direct, cable operated \\
\hline Maneuverability & $+4.0 \mathrm{~g}$ to $-2.0 \mathrm{~g}$ \\
\hline Propulsion & $\begin{array}{l}225 \mathrm{hp} \text { reciprocating engine/ } \\
\text { constant speed prop }\end{array}$ \\
\hline $\begin{array}{l}\text { Basic experiment } \\
\text { support equipment }\end{array}$ & $\begin{array}{l}\text { - Experiment platform between } \\
\text { front and rear cockpit } \\
\text { - Electrical panel for experiments } \\
\text { - Video camera and recorder } \\
\text { system } \\
\text { - Intercom voice recorder } \\
\text { - GPS navigation system } \\
\text { - Two } 70 \text { mm look-down cameras } \\
\text { - Intervelometer camera triggering } \\
\text { system }\end{array}$ \\
\hline
\end{tabular}

Figure 2.-NASA Lewis T-34B.

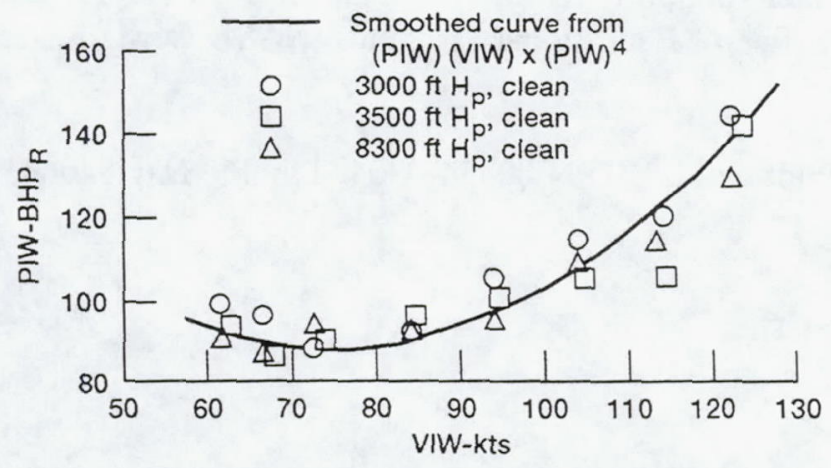

Figure 3.-Case Western Reserve University aircraft performance and stability and control experiments $T-34 B$ PIW $\times$ VIW. 


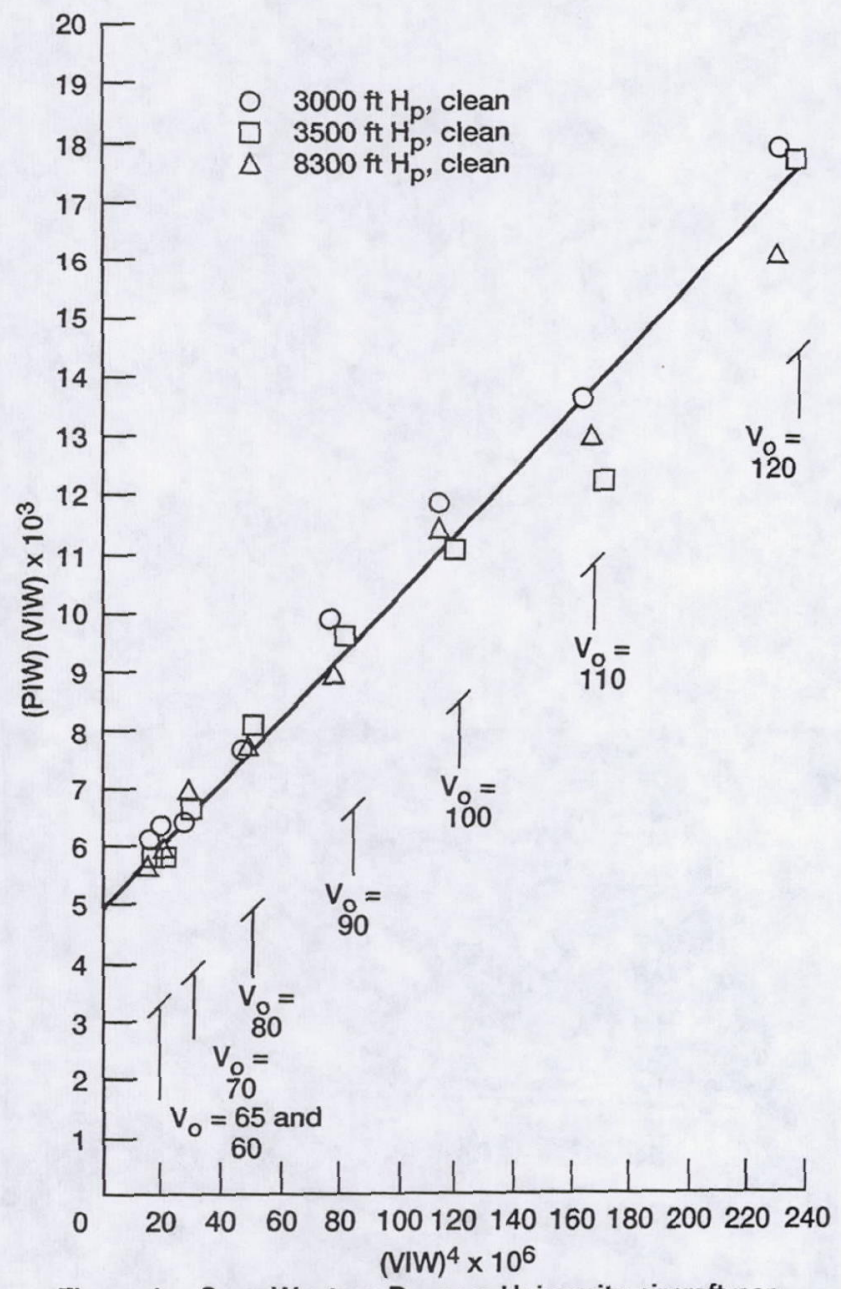

Figure 4.-Case Western Reserve University aircraft performance and stability and control experiments T-34B (PIW) $\left(\right.$ VIW) $\times(\text { VIW })^{4}$.

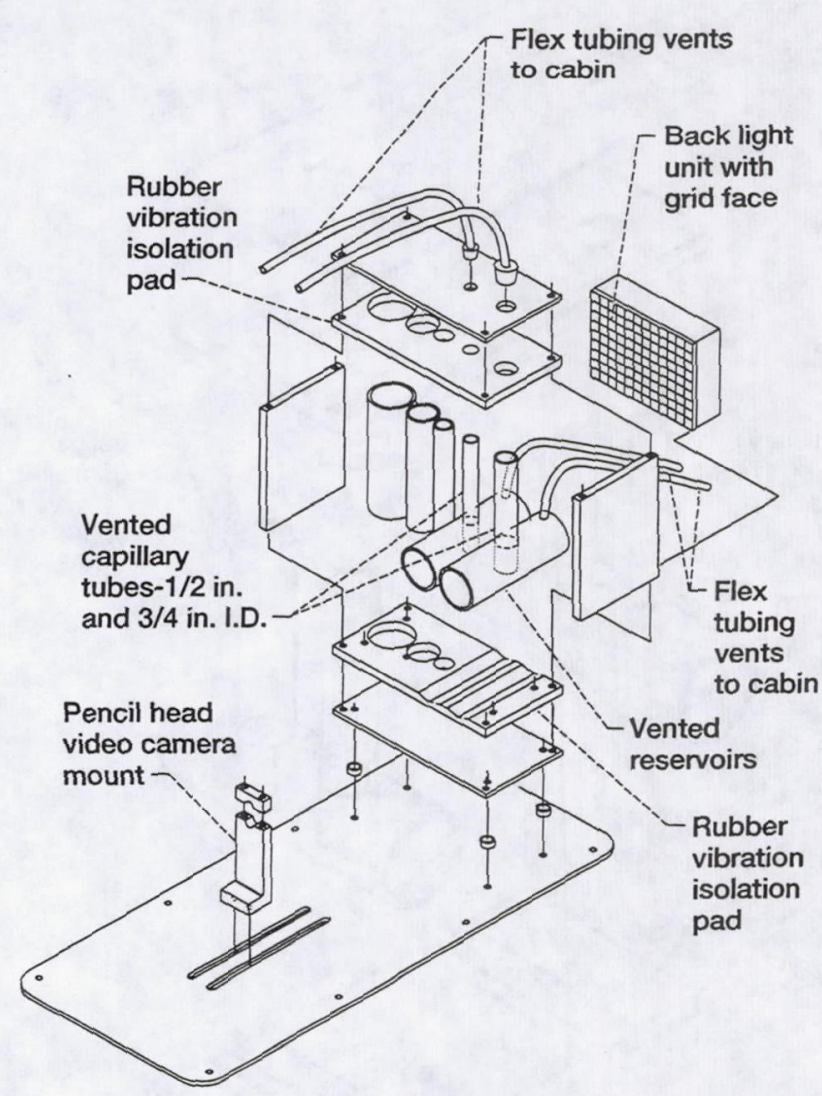

Figure 5.-Cleveland State capillary action microgravity experiment. 


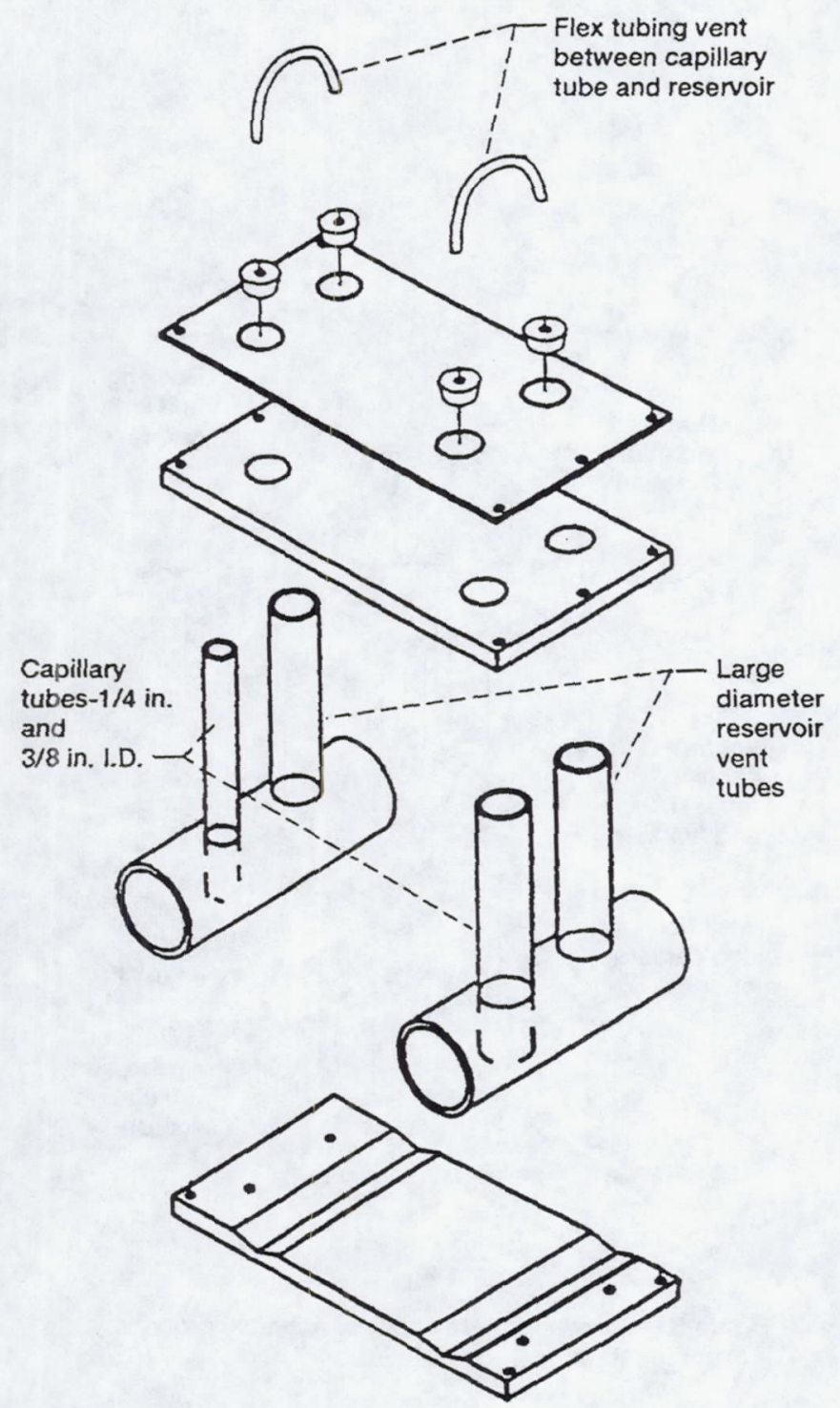

Figure 6.-Cleveland State capillary action microgravity experiment alternate capillary tube array.

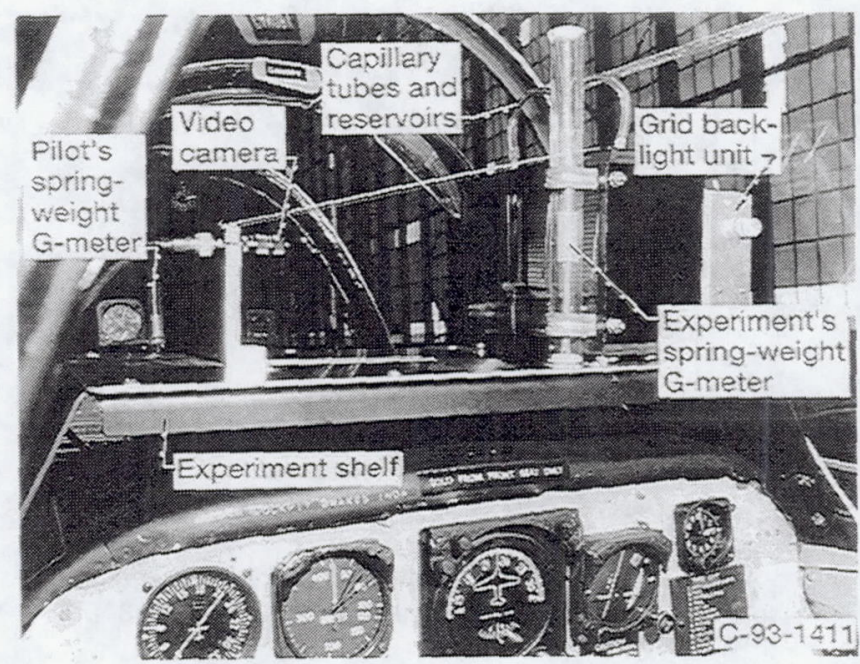

Figure 7.-Cleveland State University micro G capillary action experiment. 


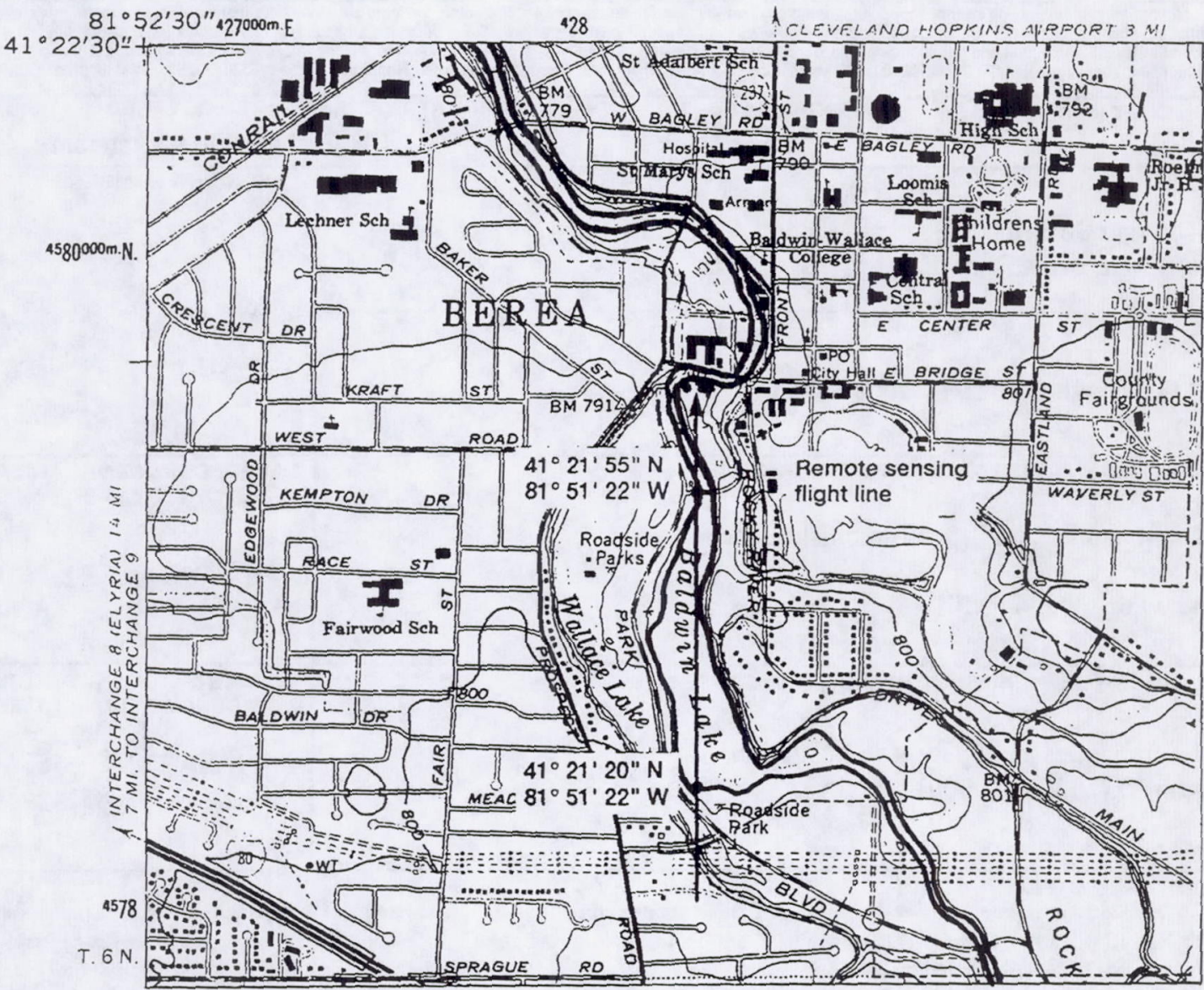

Figure 8.-Baldwin-Wallace College proposed remote sensing experiment in Berea quadrangle (Ohio). Scale, 1:24,000.

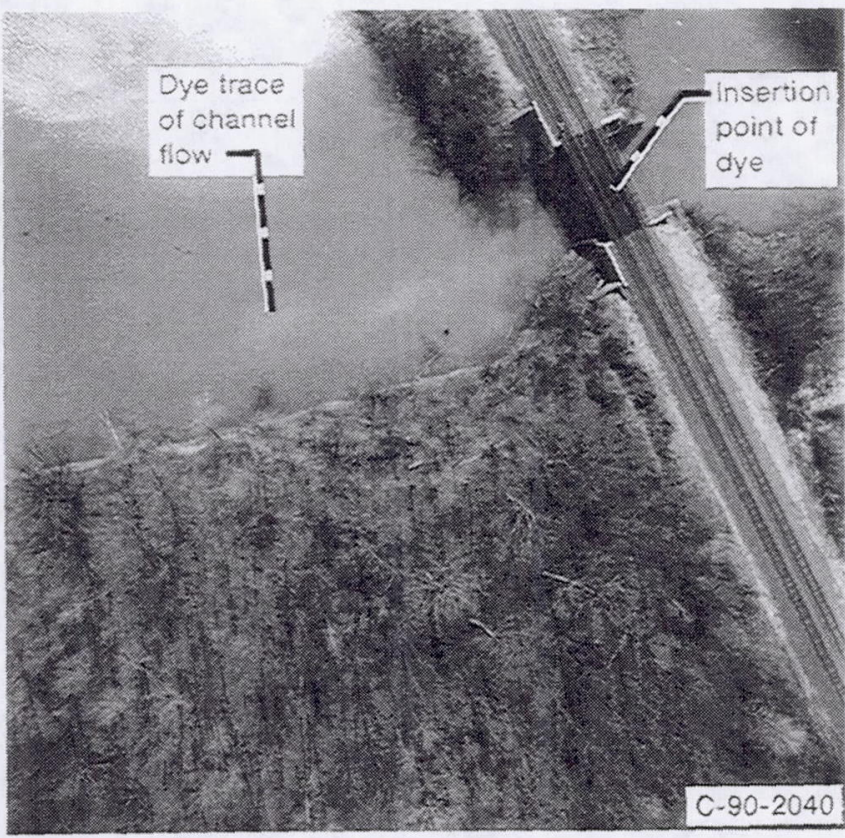

Figure 9.-Baldwin-Wallace College proposed remote sensing experiment. 
Public reporting burden for this collection of information is estimated to average 1 hour per response, including the time for reviewing instructions, searching existing data sources, ethering gollertion Davis Highway, Suite 1204, Arlington, VA 22202-4302, and to the Office of Management and Budget, Paperwork Reduction Project (0704-0188), Washington, DC 20503.

\begin{tabular}{|l|l|l|}
\hline 1. AGENCY USE ONLY (Leave blank) & $\begin{array}{r}\text { 2. REPORT DATE } \\
\text { January } 1994\end{array}$ & $\begin{array}{r}\text { 3. REPORT TYPE AND DATES COVERED } \\
\text { Technical Memorandum }\end{array}$
\end{tabular}

\section{TITLE AND SUBTITLE} 5. FUNDING NUMBERS

Roles, Uses, and Benefits of General Aviation Aircraft in Aerospace Engineering Education

6. AUTHOR(S)

WU-

Dennis P. O'Donoghue and Robert C. McKnight

7. PERFORMING ORGANIZATION NAME(S) AND ADDRESS(ES)

8. PERFORMING ORGANIZATION REPORT NUMBER

National Aeronautics and Space Administration

Lewis Research Center

Cleveland, Ohio 44135-3191

$E-8326$

\section{SPONSORING/MONITORING AGENCY NAME(S) AND ADDRESS(ES)}

National Aeronautics and Space Administration

Washington, D.C. 20546-0001
10. SPONSORING/MONITORING AGENCY REPORT NUMBER

NASA TM-106463

AIAA-94-0852

\section{SUPPLEMENTARY NOTES}

Prepared for the 32nd Aerospace Sciences Meeting and Exhibit sponsored by the American Institute of Aeronautics and Astronautics, Reno, Nevada, January 10-13, 1994. Dennis P. O'Donoghue, Sverdrup Technology, Inc., Lewis Research Center Group, 2001 Aerospace Parkway, Brook Park, Ohio 44142 (work funded by NASA Contract NAS3-25266), and Robert C. McKnight, NASA Lewis Research Center. Responsible person, Robert C. McKnight, (216) 433-2034.

12a. DISTRIBUTION/AVAILABILITY STATEMENT

Unclassified-Unlimited

Subject Category 01 12b. DISTRIBUTION CODE

Many colleges and universities throughout the United States offer outstanding programs in aerospace engineering. In addition to the fundamentals of aerodynamics, propulsion, flight dynamics, and air vehicle design, many of the best programs have in the past provided students the opportunity to design and fly airborne experiments on board various types of aircraft. Sadly, however, the number of institutions offering such "airborne laboratories" has dwindled in recent years. As a result, opportunities for students to apply their classroom knowledge, analytical skills, and engineering judgement to the development and management of flight experiments on an actual aircraft are indeed rare. One major reason for the elimination of flight programs by some institutions, particularly the smaller colleges, is the prohibitive cost of operating and maintaining an aircraft as a flying laboratory. The purpose of this paper is to discuss simple, low-cost, relevant flight experiments that can be performed using readily available general aviation aircraft. This paper will examine flight experiments that have been successfully conducted on board the NASA Lewis Research Center's T-34B aircraft, as part of the NASA/AIAA/University Flight Experiment Program for Students (NAUFEPS) and will discuss how similar experiments could be inexpensively performed on other general aviation aircraft.

\section{SUBJECT TERMS}

Education; Engineering education; General aviation; Flight test; Microgravity; Aircraft performance; Aircraft stability and control; Remote sensing

\begin{tabular}{|c|c|c|}
\hline $\begin{array}{c}\text { 17. SECURTY CLASSIFICATION } \\
\text { OF REPORT } \\
\text { Unclassified }\end{array}$ & $\begin{array}{c}\text { 18. SECURTY CLASSIFICATION } \\
\text { OF THIS PAGE } \\
\text { Unclassified }\end{array}$ & $\begin{array}{c}\text { 19. SECURITY CLASSIFICATION } \\
\text { OF ABSTRACT } \\
\text { Unclassified }\end{array}$ \\
\hline
\end{tabular}

